extrapleural, and their origin did not depend on disease cf the bony parietes.

Diagnosis. - The uncomplicated form of the disease may be confounded in the early stage with acute pleurisy. From this complaint it is to be distinguished by the presence of an extraordinary degree of local hyperæsthesia, and of pain on moving the arm of the affected side. The rapid occurrence of suppuration, together with the absence of friction, etc., will also afford valuable diagnostic aid. But when the case is seen at a later stage, the obstacles in the way of an accurate diagnosis are far more formidable. The chief difficulty is with empyema. With an ordinary empyema there is not much chance of error, but it is otherwise with the rarer forms of that complaint. When empyema is of the perforating variety (the so-called empyema of necessity) the resemblance between the two diseases is often very remarkable. They may generally be distinguished, however, by attention to the following points.

(1) Peripleuritic abscesses are unattended by signs indicating displacement of organs.

(2) They are more frequently multiple than abscesses having a connection with the pleural cavity.

(3) They do not pulsate (as is often the case with perforating empyema), they are not capable of being diminished by pressure, nor do they as a rule communicate with each other.

(4) Their size is not generally influenced by the respiratory movements. Bartels, however, states that peripleuritic abscesses do occasionally vary with respiration, increasing with expiration, and decreasing with inspiration, but these phenomena are much more likely to be witnessed in perforating empyema than in abscesses whose origin and situation are extrapleural. In my own case they were absent. Bartels also mentions that the specific gravity of peripleuritic abscesses is about 1040, while that of purulent collections originating in the pleural cavity ranges from 1028 to 1032 .

(5) In peripleuritis the boundaries of the lungs are observed to increase with a full inspiration, and areas presenting normal physical signs may be discovered between or below the different abscesses.

(6) Lastly, the diagnosis of peripleuritis will be supported by the appearance of suppuration in the loins or abdomen, and the presence of enlarged glands in the axilla of the affected side.

In some very rare instances a perforating empyema loses its connection with the pleural cavity, and becomes encapsuled in the thoracic wall, thus presenting signs that are almost identical with those of abscesses of peripleuritic origin. In arriving at a diagnosis in such cases, reliance must be placed chiefly on the clinical history; at the same time Bartels's observation as to the different densities of extra- and intrapleural suppuration may afford a certain amount of diagnostic aid.

The only other complaints likely to be confounded with peripleuritic abscesses are caries of the ribs, resulting in the formation of pus, and actinomycosis. In the former affection the probe will discover the existence of diseased bone, while in the latter the microscope will reveal the presence of the characteristically shaped ray fungus on which the disease depends.

Prognosis.-Simple cases generally terminate favourably, but when complications exist the result is much more uncertain. Many cases end fatally from pleurisy, while others succumb to pericarditis, peritonitis, acute nephritis, or to pyæmia.

The treatment of peripleuritis is mainly surgical, and is therefore considered to be beyond the scope of the present paper.

Grrman Congress of Gynacology. - The fifth Congress of the German Gynæcological Society will be held at Breslau from May 25th to 27th, under the presidency of Professor Fritsch. Among the subjects proposed for discussion are "Symphysiotomy" and "Operations on the Uterine Appendages, their Indications, Technique, and Results." Communications relative to the Congress should be addressed to Professor Fritsch, 5, Maxstrasse, Breslau, or to the First

Secretary, Docent Dr. Pfannenstiel, 1, Klosterstrasse, Breslau.

\section{ON THE ADMINISTRATION OF CARBOLIC ACID.} BY ARTHUR WIGLESWORTH, L.R.C.P.LOND.,

\section{Liverpool.}

As an administrator of carbolic acid in zymotic and other diseases for the last twelve years, I think a few observations on the interesting paper by Dr. Charteris in the BRITISH Medical Journal of December 31st, 1892, may be of some use. I may state that I have never used Graesser's acid, but Calvert's pure carbolic acid, but I apprehend they may be taken as equally pure.

The Dose. - The amount suggested by Dr. Charteris I consider to be too small if given for zymotic disease. I find the following to be average doses according to age : 1 year old 1 grain; from that up to $10,1 \frac{1}{2}$ to 2 grains; for youth, $2 \frac{1}{2}$ to 3 grains; for adults, 3 to 5 grains. Owing to a dispenser's mistake, I found that 7 grains produced irritant vomiting and purging, which ceased immediately on the dose being reduced to $3 \frac{1}{2}$ grains. (Four doses had been given, one every four hours, instead of half the quantity every two hours.)

Frequency of Administration.-My idea has been to "carbolise" the patient, and with this view I give a dose every two hours night and day, because carbolic acid is a very unstable compound, and enters into chemical combination with almost every substance with which it comes in contact, and is rapidly oxidised. From a series of observations extending over hundreds of cases, I concluded that when the urine had been rendered black by its administration, and kept so, my object had been obtained, for when thus altered it may often be kept weeks without any appreciable decomposition taking place. When I first observed the urine changing colour I was afraid it might be due to altered blood, but repeated examinations failed to detect a trace of blood even after the largest doses had been administered; and I am glad to learn from Dr. Charteris's paper the nature of the colouring matter (hydrochinon). Still, as I obtained this coloured urine when using pure phenol, I surmise it must be due to the increased quantity administered, and not altogether to impurity.

Vomiting.-I have never known vomiting produced by carbolic acid, except in the case of the excessive dose referred to, 7 grains. Indeed, in the vomiting of pregnancy, I know of no remedy so effoctual. Like every other drug, it is not infallible, but it is the first I administer, and generally in 2-grain doses. In bilious vomiting it is singularly efficacious. It is possible that there may be something in the method of preparing it for administration. I always prescribe with the mixture a few drops of spt. chloroform, and either tincture of cardamoms or orange peel to flavour it. Syrup is plentifully used, and water to make up an 8.ounce mixture. Of this one tablespoonful is ordered, to which is to be added two or more of water. In this way an agreeable fluid drink is made, freely partaken of by both children and adults. Only one instance do I know of in which a child refused to take it, but, as all medicine was equally refused, I do not take this into account. I think if a mixture so prepared is ordered in future, and careful observations made, it will be found that vomiting will be allaved rather than excited by its administration. indeed, I fail to see from what cause vomiting should arise, for in these doses, 1 to 5 grains freely diluted, it acts more as a sedative than an irritant. I can quite understand that in pills it might cause vomiting, or rather that the pills caused vomiting, for retching is often excited by swallowing even bread pills.

Effects on Temperature.-I do not think that carbolic acid per se has any effect in lowering temperature.

Its Use in Zymotic Diseases. - If given in doses of 4 to 5 grains every two hours in the initial stage of puerperal septicæmia, it generally stamps it out in from twenty-four to thirty-six hours, and in the later stages, combined with the administration of quinine in alternate doses, it is most effectual. In cases of apprehended puerperal septicæmia I commence its administration.within twelve hours of completed labour with great success.

As a Prophylactic in Scarlet Fever.-Whenever a case of scarlet fever originates, I at once put all those in the house who have not had the fever on carbolic acid-2-grain doses twice a day. In a large number of cases the outbreak has 
been confined to the one first affected, and if any others have subsequently taken it, the attack has been singularly mild. The following is a good illustration :

On November 4th a child, aged 10, took a severe attack of scarlet fever, when all the other children-one older, four younger-except the baby, 18 months old, took 2 grains of carbolic acid twice daily. In four days nother child was taken ill, but the attack was much milder. The mother mixed promiscuously amongst them. The baby was unavoidably in the sick room much of the day and during the whole of the night. the end of three weeks, whilst desquamation was active, the baby took scarlet fever, but in such a modified form that it could be scarcely said to be ill; the rash was transient and she was well in a week. There was no desquamation in her case. None of the other three children have taken it. They took the acid until the house was disinfected.

I could multiply such instances did space permit. In conclusion, I may say that, after twelve years' experience, I know of no therapeutic agent to equal it in efficiency, and have never seen any untoward result arise from its careful

If I might venture into the domain of theory, I would suggest that the spores of the pathogenic microbe which produce scarlet fever have either a feeble investing membrane or are peculiarly subject to the influence of carbolic acid; hence they are rendered incapable of vigorous multiplication, each succeeding generation becoming more attenuated. Therefore, when transferred even to fresh pastures they are too feeble for active development, and a mild attack is the result.

\section{MEMORANDA}

MEDICAL, SURGICAL, OBSTETRICAL, THERAPEUTICAL, PATHOLOGICAL, ETc.

\section{PROLAPSE OF THE UMBILICAL CORD.}

Trat cases complicated with prolapse of the umbilical cord occur now and again is the experience of most men in large midwifery practice, and the treatment pursued is pretty much the same by all, and I have always adopted the recommended treatment in my cases during the past twelve years with varying success. In former cases I found that the replacing of the cord was frequently attended with difficulty, and after being replaced well beyond reach invariably descended with the advent of each successive labour pain. Under these circumstances it was my habit to turn immediately or apply the forceps, and so hasten delivery, believing that if left alone the child would certainly be asphyxiated. Two cases I have had within the past month and the treatment adopted I have thought worthy of mention.

Casu 1. - C. B., aged 34, single, multipara. Her former labours had been normal. I was called to her in the Poorhouse at 9 P.M. on December , 1 inguor amnil having escaped about 9 A.M. With a rush and without warning. On examination I found tho os cecond obstetrical position wh a loop of cord, which was thick and dis tended, lying posterior to the head and well down in the vagina. Having several times put back the cord and finding it always came down again, applied the forceps and so completed delivery. The child was well nourished, at full time, and was born alive. During delivery the cord ruptured, and there was troublesome hæmorrhage from the placental wh interior, and external pressure.

CasE II occurred in private practice. Mrs. L., aged 29, multipara. I had attended her in former confinements (four), all of which were nor mal. I was called at 7 A.M. on January 12th. The patient had been in labour for three hours, pains every fifteen minutes and fairly strong. ound a large bag of "waters" distending the vagins, the os about th size of a crown, piece and quite flaccid, the head could just be reached with the examining finger, and 1 could feel the umbilical cord between my finger and the presenting head. In this case turning could have been ocomplished rather easily but I determined not to, but ruptured the membranes and await Nature's process of accomplishing the labour in interfereif there was any spmptom of danger to the life of the child. in time became fully dilated, and the head entered the chid. The

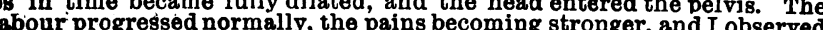
examining during every pain) that, as expected, the pulsation in the ord stopped the cord becoming tense and coiled up, when the ho in the ressed it against the bony pelvis, but after the pain tos over and the hesd had receded the pulsation returned. This was thas over and the - alternate advance of head no pulsation in the cord, recession of head ulsation. When the head came down on the perineum I pulled out the oop of cord, and the next pain expelled the head, the bodp followine ith another pain, that is, the whole child by a "double" pain, at
9 A M., two hours after $\mathrm{my}$ arrival. The child was alive, healthy, and

In the two cases mentioned the dimensions of the pelvis were normal. After the above experiences there seems to me to be no necessity for immediate active interference in every case of prolapse of the cord, either by version or applying the forceps, other things being equal, when one has replaced the cord and failed to keep it in situ, but allow Nature to use her own means of delivery, the accoucheur meanwhile paying close attention to the pulsation or non-pulsation of the cord during the progress of the labour.

Aberdeen.

JoHN G. Scroggte, M.B., C.M. Medical Officer to the City Poorhouse.

\section{TREATMENT OF SYPHILIS BY MERCURY AND HOT} BATHS.

I RRAD Dr. Alexander's letter on the above with interest. I agree with all he states. Many years ago I visited Aachen in order to see for myself the method which had proved so successful in curing the syphilised at that spa. The town and surroundings I found most depressing; the waters are very weak sulphurous springs, identical with the mildest sulphur springs of this place; they vary in temperature from $114^{\circ}$ to $170^{\circ}$, and resemble Bath in being thermal, but in nothing else. The main thing at Aachen is the thoroughness of the inunction. This is done by highly-trained men and women. and it only can be done effectually by such.

I saw patients who had undergone thirty, forty, and sixty inunctions going about as usual. Some had been sent away after thirty rubbings to Carlsbad, Homburg, etc., and had returned-100 inunctions being occasionally enforced without any marked or unpleasant physiological mercurial symptom arising except in the steady diminution of eruptions, nodes, ulcerations, and nocturnal pains. I saw several non-specific cases of chronic eczema, lichen, and psoriasis undergoing this treatment. Since my visit to Aachen I have treated a very great number of cases by inunction, both in combination with our sulphur waters and baths and without either. The result has been most satisfactory, but I have found more rapid improvement when the waters supplemented the rubbings than when mercury alone was employed. This has been especially the case where the mucous membrane was affected. I have had four severe cases undergoing treatment during the past frosty weather; they have been out every day. Two I have had to treat entirely by mercurial rubbings, and to allow them to rub themselves; the other two have been rubbed by a medical rubber, and taken the mild sulphur water daily internally, and a sulphur bath every other day. The progress made by those on the sulphur water has been very much greater than the others, although their symptoms were more marked and of longer duration.

Harrogate. A. S. Myrtle, M.D.

SCARLATINA AND ROSEOLA.

THe diagnosis of scarlatina has always been a difficulty. This fact was emphasised a few weeks since in a letter in the BRITISH MEDICAL JOURNAL, by the medical officer of a small scarlet fever hospital containing thirty beds, in which he stated that out of thirty patients sent to him and certified by medical men as being cases of scarlatina, no fewer than ten cases proved not to be scarlatina at all.

I have had a singular experience in a large institution to which I am attached as medical officer, wherein at the end of December, 1891, a solitary case of roseola occurred, the child was carefully isolated, and it appeared that the disease was stamped out.

Three months afterwards, that is in March, 1892, no fewer than 31 cases of roseola presented themselves with all the characteristic symptoms, namely, a flush over the chest, no sore throat, no elevation of temperate, and no complaint of illness. The same care was adopted as before, and another period of three months or so passed without a case appearing.

The drains having been found defective, the children were sent away from the institution. while the whole system of drainage was rendered as complete as science and good workmanship could produce. One hundred children were sent home to their friends, and one hundred who were friendless were taken to Clevedon for two months. While the home was 